\title{
Fast Fashion In A Flat World: Global Sourcing Strategies
}

Barbara Mihm, University of Wisconsin- Stevens Point, USA

\begin{abstract}
The following research offers a theoretical model for understanding sourcing decisions made by apparel retailers. The concept of fast fashion is explored by applying the model to Zara and Kohl's. Factors influencing sourcing decisions are noted, and financial results of the retailers are compared. Finally, ideas for future research using the model are offered.
\end{abstract}

Keywords: Fast Fashion, Retail, Supply Chain Management, Global Sourcing, Merchandising, Zara, Kohl's

\section{INTRODUCTION}

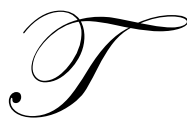

he next time you are looking through your closet, inventory which items are "Made in the USA." Chances are your list will be very short since less than 5 percent of all apparel sold here is made in the United States (CNN News, 2009). Our closets are a microcosm of the shift in manufacturing due to globalization and reflect the huge influx of clothing imports into the United States.

To illustrate this point, in 1982, US textile and apparel imports were 10 billion dollars. In 2006, the figure was 96 billion (U.S. Department of Commerce). The Agreement on Textiles and Clothing Act was negotiated under the World Trade Organization (WTO) in 2005 and it removed quota restrictions for all apparel and textile imports for the 145 members of WTO. The trend of manufacturing fashion goods outside the US has resulted in lower costs to the consumer, and the look is not only cheap, but surprisingly cheap chic.

The impact of global trade in apparel has spawned the concept of fast fashion, apparel produced quickly with a low cost, chic look now dominating the retail world. Fast fashion is mass-produced, reasonable in price for most consumers, and easy to obtain, making it simple for anyone to look stylish. Tom Ford, the iconic designer who spent years with Gucci, proposed that the concept of fast fashion makes fashion democratic, because it is affordable and fashion is no longer dictated by an elite few (Agins, 2007). Both H \& M and Zara pioneered the concept in the 1990's opening stores in major US cities. The first openings of H \& M in the States prompted customers to line up outside the store waiting to get in to buy clothes that were cutting edge with the latest look but reasonably priced.

Traditional cycles prior to the advent of fast fashion took about six months from design to store availability; fast fashion today means a cycle of four weeks or less. Additionally, fast-fashion firms such as Zara tend to continuously re-stock shelves with new items as opposed to the traditional seasonal approach, increasing the motivation for customers to buy a product before it is off the shelf and gone for good.

The following discussion contrasts two very different methods of achieving fast fashion using a theoretical model comparing Zara, a specialty store retail leader, with Kohl's, a successful general merchandiser exclusively selling a line of Vera Wang apparel. Using the model to compare characteristics of the different methods, the research offers a better understanding of the decisions firms face in sourcing and issues along the supply chain. Finally, key financial measures are used to compare the outcomes of each firms sourcing strategy.

\section{A MODEL FOR UNDERSTANDING SOURCING METHODS}

The era of globalization opened country borders for the sourcing and selling of apparel. And in a sea of sameness, retailers try to differentiate their products by branding. While there can be many variations on product 
sourcing for apparel retailers, there are three basic methods a retailer can use in sourcing brands carried exclusively by that retailer. These methods can be depicted on a continuum, moving from high levels of control to lower levels of control (see exhibit 1).

On the left side of the model, a firm uses vertical integration and controls all parts of the design, manufacturing, and distribution procedures; this is known as full vertical integration. In this case, the retailer owns its own factories and distribution centers. The second method in the model occurs when a retailer contracts with a manufacturer using designs handled in-house. In this case, the retailer supervises the design and manufacturing processes, to meet their internal quality standards and design specifications via direct contact with a manufacturing plant. The retailer does not own the factory but contracts with the factory of its choice. The retailer might also handle logistics, including contracting with a firm to transport goods from the manufacturing location, clear customs, and arrange for transportation to a distribution center. This method is typical for store brand private labels and is known as house branding. The third method would include partnering with an outsourcing expert to handle all parts of the process, beginning with design, moving to manufacturing, and finally handling the logistics to get an apparel item to the retailer's floor. This is a fully outsourced method. The retailer has contact with the outsourcer, not the manufacturing plant.

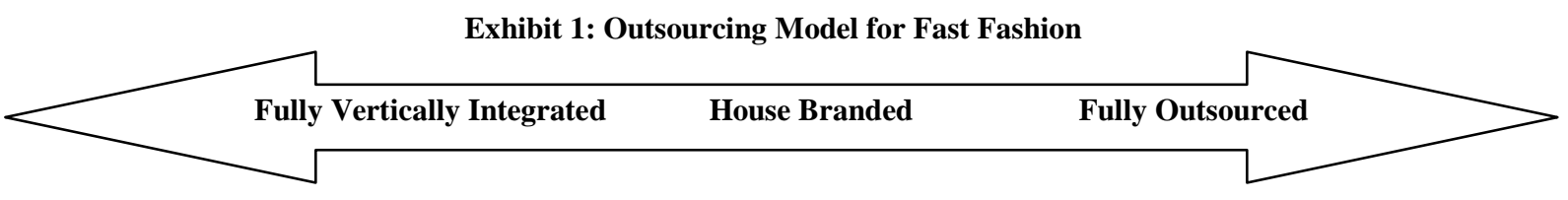

A number of factors influence where a retailer falls in the sourcing model. These include labor costs, price point of goods sold, use of technology, market responsiveness, and involvement in the supply chain.

Lower labor costs are a major contributing factor to fast fashion since cutting, sewing and fitting are labor intensive, and are integral parts in constructing apparel. While tasks are labor intensive, the skills needed are easy to acquire and workers do not need high levels of education. Additionally, capital equipment costs are very low, making it easy to open an apparel plant almost anywhere. Labor rates in China are about 60 cents per hour, with less developed countries having even lower labor rates. However, low cost labor is not the only reason that many can dress stylishly for less.

Fast fashion is not about high prices, and low labor costs are a central part to keeping the price of the product low. Fast fashion is not haute couture, customers expect to find fast fashion at moderate price points and low labor prices are an integral part of the concept. In fact, consumers do not view fast-fashion clothing as an investment. Purchases are made frequently, and often are worn for only one or two seasons. This is a very different concept from designer goods that consumer view as fashion investments. Since labor costs are the major portion of the production cost in moderately priced apparel, keeping labor costs as low as possible makes sense. Low cost goods and low cost labor go together to drive fast fashion but other important factors also influence sourcing decisions.

As Friedman (2005) noted in we are in the third era of globalization, where technology plays an important role in facilitating connections between businesses in far flung parts of the world. There are a number of major technological influences supporting the development of fast fashion (Moore \& Fernie, 2004). First, and fundamentally, is the existence of highly networked and flexible suppliers. An example of a key player in this supply network is Li \& Fung Company, which supplies over eight billion dollars in clothing and consumer goods for world-renowned companies from plants world-wide (Fung, Fung \& Wind, 2007). Flexibility also includes changes in the construction and coloring processes used to make garments. In fast fashion for example, garments are often dyed after they are constructed thus allowing the manufacturer to produce the best selling colors quickly. 
Information technology (IT) communication systems also play an important role in fast fashion. IT systems can quickly capture information on trends, and share production and shipping data, thus facilitating real-time communication along the supply chain. For example, firms like Zara pride themselves in their ability to pick up on a fashion trend from the runway and transform the concept into a Zara product within days of the fashion show in Milan or Paris. Designers, fabric suppliers, and manufacturing facilities are in constant communication through IT systems.

Information technology also impacts production. The apparel industry makes use of computer-aided design (CAD) technology in both cutting of fabric and in automated sewing machines. CAD eliminates wasted fabric and laser equipment cuts multiple layers of fabric at once with tremendous accuracy. However, even with these improvements, the making of garments is still highly labor intensive. A worker individually sews and presses each garment. Trim, zippers, and buttons all need to be applied to each garment individually, often involving timeconsuming hand work.

Improved logistical programs including air freight and expedited customs clearance for imports also fall within the technology factor. Companies that previously were simple exporters, now are providers of end -to-end services and are viewed as coordinators of the supply chain, providing world-wide souring, coordinating design, manufacturing, and logistics (Fung, Fung \&Wind). All of these influences have dramatically changed the way the apparel business operates in the age of globalization, making the fashion industry appear borderless.

Fast fashion and market responsiveness seem to be inseparable. However, some firms selling fast fashion can respond quicker to market needs than others. Firms that respond quickly to customer needs are seen as trend setters. Market responsiveness includes not only introducing new fashionable apparel influenced by trends, but having the right amount of product in each individual store. Predictive models through the use of information technology can play an important role in customer responsiveness. Predictive models can help with more accurate allocation of inventory to the individual stores. Often firms that use a pull system, allowing individual stores to control their merchandise, rather than a push system, where corporate dictates the entire line up are more locally responsive.

Allocation of merchandise quantity is also an important part of market responsiveness. Research shows that allocation of the right amount of product to individual stores is a key part of profitability (Levy \& Weitz, 2009). Having the right quantity to support market demand, but avoiding markdowns on excessive inventory is critical. The ability for stores to reorder hot selling products also comes into play under market responsiveness.

The last factor that influences sourcing decisions is how much involvement in the supply chain a retailer wants to pursue. Some retailers are interested in involving only themselves with parts of the supply chain. For example, Wal-Mart has been known to handle logistics better than most outsourcing options. Firms that can execute all parts of the supply chain have large control in sourcing. If a firm relies heavily on designer brands for merchandising, it relinquishes control to the designer and to a third party who manufactures the goods. Firms that sell mainly their own brand tend to exercise more control over their merchandise, often being directly involved with the selection of a manufacturer. In general, as supply chains get longer, meaning more players are involved with the completion of a garment, the more difficult it is for the retailer to control the various parts of the supply chain, the actions taken by the various players.

In many cases the focus of the retailer dictates the level of involvement. A retailer may focus on the manufacturing function involving themselves with tasks under manufacturing, while in other situations the retailer may focus on the marketing function, being more focused on marketing tasks such as logistics, advertising, placement of merchandise in the store, and point of sale information.

\section{ZARA'S METHOD}

Zara, the Spanish firm owned by Inditex has begun to dominate in the US after a strong retail life in Europe. In 2009 Zara overtook the Gap as the world's largest specialty clothing retailer. Zara started as a lingerie shop in La Coruna, in 1975, and became incorporated within Inditex in 1985 (Keeley \& Clark, 2008). The 
corporation went public in 2001, and Business Week lists it as number 62 of Best Global Brands conducted by Interbrand, with a 15 percent increase in brand value for 2008 over 2007. Brand value is calculated in a method similar to how other corporate assets are evaluated, an estimate of future earnings the brand can bring in (The 100 Top Brands, 2008). Zara continues to pile up brand value with a 14 percent gain in 2009 over 2008. Business Week noted Zara as one of the biggest winners for 2009 (Helm, 2009). While the parent company has other brands, Zara is the largest contributor in sales and profitability. The Interbrand ranking includes only the Zara brand (Rohwedder \& Johnson, 2008).

An explosion of store openings in the US and 60 other countries replaced Zara's initial approach of slow and steady growth, bringing the current total to 1058 stores. Zara has 30 locations in US cities with a goal of 50 stores in the US by 2009. Even in a tough world economy, as others close stores, Zara plans to open 640 new stores in 2008 (Capell, 2008). Major European cities have a Zara store every few blocks, busy with customer traffic. The store name has become a well recognized brand in Europe through what some term the 'oil stain' method of growth. Zara establishes a flagship store, to build recognition and create buzz in the new location. It then adds smaller specialty shops, for various product lines capitalizing on the name brand. In this way a density of stores helps create economies of scale and aids in boosting profit margin (Keeley \& Clark, 2008). For example, in Milan or Paris a shopper can expect to find a flagship Zara store on one corner and a Zara Home store less than two blocks away.

Zara's method of sourcing product is very different from the traditional methods used in the fashion industry because the company controls every part of the supply chain. Instead of using an outsider to design the clothes, the firm uses 300 in-house designers and relies heavily on store managers' input. Using information technology the store managers track selling trends real-time through IT systems connected to headquarters. However, more importantly store managers detect what customers are looking for but do not find in the stores. This collaborative effort between store managers and the company designers results in an industry record: new products are designed and placed in the stores within two weeks. Using e-collaboration tools, from store to corporate design offices in Spain, Zara employees help forecast fashion trends instantly giving Zara a competitive advantage in speed (Capell, 2008).

And speed it not limited to the design of new product. Vast quantities of neutral fabric are stocked at production facilities, which can quickly be dyed or printed to speed up production of better selling colors (Fry et all, 2007). While a small amount of fashion basics like tee shirts are ordered from other sources, the vast majority of products are manufactured in Europe at Zara owned facilities. All of the fast-fashion clothing going to Zara's stores passes through its own distribution center in the Northern part of Spain, helping to consolidate shipping (Dowsett, 2008). Zara copied JIT methods from Toyota and shipping on the continent takes only 24 hours. Asia and the US shipments take 48 hours. While shipping cost are higher using commercial airlines, versus sea transportation, batches are smaller making this type of shipping cost effective (Capell, 2008).

The difference is not only fast, but fresh. Rather than the traditional six seasons each year, the stores change clothing about twice a week. The collections are small and often times sell out creating an air of 'get it now' with shoppers and require few price reductions. Some best selling items are reordered by store staff and replenished quickly (Rohwedder \& Johnson, 2008). Store managers have a vested stake in the sharing of ideas, since store sales weight heavily into their salaries (Capell, 2008). However, while there is some localization, the majority 85 percent of product line up is standard from country to country, with about 15 percent varying for local tastes (Fry et all, 2007).

A sophisticated inventory optimization model developed by faculty, graduates and a student intern from MIT Sloan, supplements the manager's intuition. The forecasting model is an information system based on historical data that can calculate a demand estimate for individual stores to maximize sales as a whole. For example, if inventory is allocated using the analytical model based on historical data, it lessens the odds of stores being stuck with too much inventory and instead gets more quantity to stores that are apt to sell more (MacMillan, 2006). Predictive modeling systems combined with a strong fashion sense help the products fly out the doors. 
European firms pioneered the concept of fast fashion; the idea has caught on with other retailers. For example, Kohl's has been successful using private labels to increase profitability and create an aura of exclusivity. Kohl's also recognized the importance of speed in the apparel business. Kohl's claims to be working with suppliers to reduce cycle time by 12 weeks (Company News, 2007). However, it appears that specialty stores can run circles around a general merchandiser in terms of turnaround time (see exhibit 2).

\section{KOHL'S METHOD}

Kohl's Corporation is not a global retailer; instead it is a large national mass merchandiser, with over 1000 stores in 47 states. Based solidly in the Midwest and headquartered in Milwaukee, Wisconsin, Kohl's uses a discount method of pricing heavily promoted with newspaper inserts and constant sales. Branding is a key to its strategy with national brands, in-house brands and exclusive designer agreements making up its merchandise selection in apparel. It has a marketing focus using heavy promotions and point of sale signage.

Kohl's strategy has been to increase its commitment to more private label brands. Kohl's expected its sales, which were 16.47 billion in 2007, to be supported by 28 percent of in-house private label brands and 11 percent by its exclusive designer brands, including the Simply Vera Vera Wang collection (O'Connell, \& Tan, 2008). The Simply Vera Vera Wang line was introduced with great fanfare at Kohl's in fall of 2007, including women's clothing and accessories, along with other soft goods such as linens and towels. Expectations were high for this exclusive agreement. By the third year of the agreement, Kohl's anticipated 500 million dollars of business (Hoovers, 2008).

In an interview from September of 2007 for the Wall Street Journal as Kohl's launched the line, Wang was asked about the risk of watering her name down in the mass market. Her comments admitted that the agreement was a risky one.

The Kohl's line is about being comfortable, edgy, whether you are wearing a $\$ 20,000$ dress or a $\$ 20$ top. It could be for my teenage daughter, a young working professional woman, or a young mother. Even a middle-age mother. It's not about age. Kohl's is about ease, and a comfort, and you can throw it on. It can be put together, you can make it part of your own wardrobe. But at every price point, you have to ask how to really make it worth the money. When a top is $\$ 1,800$, the question is: Does it look different enough, is there enough technique, are there enough decorative elements that make a woman feel this is worth \$1,800? For the Kohl's client, who might be weighing whether to spend $\$ 138$ versus $\$ 80$ for a top, the question is: Is there enough to justify the price, in the detailing of the cuff or the texture and the fineness of the wool? Does it feel worth it? That's the challenge you face at every level (O'Connell, 2007).

In the Kohl's method, the firm entered into an exclusive licensing agreement with Vera Wang basically paying for the rights to the name. While the Simply Vera Vera Wang name is on the product, the largest outsourcing firm in the world, Li \& Fung, handles the entire process from completed designs to placement in the stores. This 100 year old Hong Kong firm, has over 1000 customers with its largest customer being Kohl's (C. Tsy, personal communication, 1/11/2008). Li \& Fung has coined the term 'network orchestrator' to describe the method it uses as being the channel master in outsourcing over 8,300 suppliers in countries throughout the world (Fung, Fung \& Wind, 2008).

The role Li \& Fung plays is not limited to making and shipping the clothes to Kohl's. "Li \& Fung serves as the eyes and ears for its customers, offering design services and monitoring customer trends"(Fung, Fung \& Wind, 2008, p. 121). By sharing fashion trend information with clients and passing information on fabrics and other design elements from suppliers, Li \& Fung is able to move itself up in the value chain becoming an integral part of Kohl's business strategy, providing illusion of high end fashion with the Vera Wang name, at a low cost price because of its sourcing agreements. To make this work, the sharing of information between Kohl's and Li \& Fung is essential. Kohl's does its part by keeping an eye on fashion trends through its design office in New York's Garment District. This office opened in January of 2007 and was set up to facilitate design development for licensed products, particularly the Simply Vera Vera Wang line. 
An article in MIT Sloan Management Review (Bitran, Gurumurthi \& Sam , 2007) details the important role firms like Li \& Fung play in the supply chain for retailers. Noting the importance of retail powerhouses like Kohl's that want to focus efforts on the marketing function rather than the manufacturing function, the article highlights the role Li \& Fung plays as a "mini-maestro" working with thousands of suppliers in 40 countries. In fact, Li \& Fung refers to the world as its factory floor (Fung, Fung \& Wind, 2008).

To better understand the importance of this role, Bitran, Gurumurthi \& Sam state: “ Li \& Fung coordinates each process in the supply chain: raw materials sourcing, factory sourcing, manufacturing control, shipping consolidation, customs clearance, and local forwarding logistics" (2007, p. 34). This "integrator role" or "minimaestro" as Bitran, Gurumurthi, \& Sam describe it, has close relationships with it supplier base, and is able to change suppliers and shippers based on various constraints including time-frame requirements. Its advanced logistical system allows for maximum flexibility. Indeed, the entire manufacturing process is broken up and dispersed throughout the globe.

The goal is optimization of the supply chain, and the "doors and roof of the factory are ripped off" (Fung, Fung \& Wind, 2008, p.6). "Network orchestration" as depicted by the authors involves supply chain management in the flat world, where country boundaries are eliminated, and optimal suppliers are coordinated via the channel master. Information technology systems make the borderless factory possible. The expert team at Li \& Fung Hong Kong headquarters, via a video connection, can solve a manufacturing problem at a remote plant. Digital photos and video conferencing help communicate client specifications with the factory floor with Li \& Fung as the connection point. PDAs are used on the factory floors to quickly upload information to account managers in Hong Kong, as well as to the end client (Fung, Fung \& Wind, 2008).

Information technology combined with global expertise, is why Li \& Fung is a master at sourcing. In fact, a piece of apparel with the Simply Vera tag and sourced by Li \& Fung for Kohl's is truly global, with yarn, completed fabric, zipper, button, thread, and assembly all being competed in different factories, often in different countries. The Simply Vera dress purchased in the States is more global than its owner could ever hope to be.

Generally, retailers like Kohl's should be able able to maintain a higher profit margin on their exclusive lines of goods relying less on markdowns provided the merchandise sells well in the season in which it is introduced. However, the danger is that the retailer pays a minimum fee to the designer for the use of the name regardless of sales (O'Connell \& Tan, 2008). And with Kohl's heavy promotional strategy, the design label is rarely sold at regular price. Continuing investigations showed Kohl's consistently marks down the current season merchandise of the Simply Vera line about 40 percent across the country. Out of season goods are typically marked at 80 percent off. The practice of continuous mark-downs and heavy discounting significantly erodes profits, while diminishing the value of the designer name in the customer's mind.

In the model, Zara falls to the far left of the continuum, vertically integrating all aspects of the apparel manufacturing process, while Kohl's falls on the other end of the model handing tasks to an outsourcer. The firms represent two extreme placements on opposite ends of the model (see exhibit 2).

Exhibit 2: Outsourcing Model for Fast Fashion Model Including Retailers

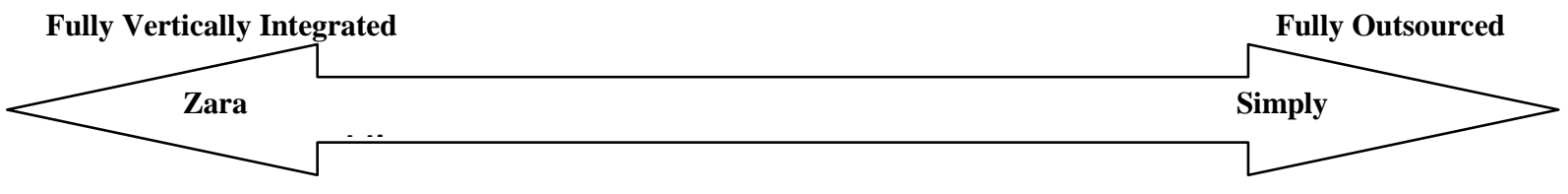


Exhibit 3: Characteristics of Retailers as Applied to the Outsourcing Model

\begin{tabular}{|c|c|}
\hline Characteristics of Zara's Method & Characteristics of Kohl's Method \\
\hline Develop Designs In- House & Pay for Designer Name \\
\hline Manufacturer Own Products & Designs Completed by Li \& Fung \\
\hline One Distribution Center in Spain & Outsourced Manufacturing by Li \& Fung \\
\hline Coordinate Shipping 24-48 Hours & Shipping by Li \& Fung to Regional Kohl's Warehouse \\
\hline Small Batch Production & Larger Batches \\
\hline New Product Twice per Week & 6 Collections per Year \\
\hline Vary Prices by Location by Country & Standardized Pricing \\
\hline Communication Upward from Stores= Pull System & Communication from Corporate $=$ Push System \\
\hline Avoid Markdowns on Leftovers & Heavy Markdowns in Season 40-50 \% Off \\
\hline Maintain High Profit Margins & Lower Profit Margin than Anticipated \\
\hline Customer Identifies Brand with Store & Just One of Many Brands \\
\hline Very Little Advertising & Heavy National Advertising \\
\hline No Sales on the Internet $*$ & Heavy use of Internet for Sales \\
\hline
\end{tabular}

*Zara announced a move for Internet sales to begin in 2010

\section{Financial Measures}

While the economic meltdown certainly confounds measuring the overall success of any retail method, it appears that Kohl's method of outsourcing its merchandise does not compare to the tight execution that Zara is able to use with a strict method of vertical integration. The following table details the financial performance for the firms as reported in Hoovers (see exhibit 4).

Exhibit 4: Comparison of Financials

\begin{tabular}{|l|c|c|}
\hline \multicolumn{1}{|c|}{ Measurement } & Inditex Dec 2008 & Kohl's Jan 2009 \\
\hline Number of stores & 4265 & 1004 \\
\hline Revenue & 13,947 Millions of Dollars & 16,389 Millions of Dollars \\
\hline Total Net Income & 1895.4 & $6,05.0$ \\
\hline Gross Profit & $7,907.0$ & $5.4 \%$ \\
\hline Net Profit Margin & $13.3 \%$ & $13.1 \%$ \\
\hline Return on Equity & $30 \%$ & $3.7 \%$ \\
\hline Inventory Turnover & $31.3 \%$ & $.5 \%$ \\
\hline 1 Year Sales Growth & $9.4 \% *$ calculated from financial statements & \\
\hline
\end{tabular}

\section{CONCLUSIONS}

Clearly, the sourcing strategy used by Zara's parent company Inditex, is providing significantly better financial returns. The fact that revenue reported by Inditex for the year was less than Kohl's but gross profits was substantially higher is the key to why Inditex has a much higher profit margin and return on equity. Inventory turns are significantly better and this number represents the entire company, not just the Zara stores. A calculation for Zara only would be even higher. Perhaps most telling is the sales growth comparison. In a down economy Inditex grew at 31.3 percent, with Kohl's nearly stagnant at .5 percent.

It is important to note some other big differences. Inditex has multiple store formats; Kohl's does not. Inditex operates a small percentage of their stores in franchise agreements, while Kohl's has no franchise agreements. Inditex is operating globally, while Kohl's only has stores in the US. The biggest part of Inditex business is Zara, which sells only women's apparel. Kohl's is a general merchandiser, and reports 32 percent of its sales in the women's category (Kohl's Corporate Report, 2008). Finally, the location and format of the each firm's stores is entirely different. Zara stores are small in high rent high traffic areas in major metro areas, while Kohl's stores are large in suburban shopping areas.

Another difficulty with Kohl's approach is that the Vera Wang brand was scaled down to fit the Kohl's price point but then failed to achieve the status that is inherent with the name of the designer. Furthermore, the chain 
failed to communicate the concept to store staff. Initially, clerks were not aware of which products were Vera Wang, and the displays were sloppy. While a separate section of the women's department is devoted to Simply Vera Vera Wang, the display does not create the feeling of exclusivity; instead falling into Kohl's typical discount department store look.

As Steve Chang predicted in Brandweek in October of 2006, the fact that Kohl's lacks a unique apparel position may be hampering sales. Simply Vera appears to simply be too much for the Kohl's bargain hunting customer. And the real Vera Wang customer, familiar with the Very Vera line, must be disappointed with the lack of personal attention and shoddy display of what was once considered exclusive. Mass market may be mass mistake, failing to achieve the goal. When interviewed at product launch, Peggy Eskenasi Executive Vice-president for product development, spoke about Kohl's branding goal " what we have been trying to do with Vera ... and all of our exclusive brands is to try to make Kohl's a destination. If she wants Vera, she'll come to us" (Nolan, 2007, p. 20). It will be interesting to see how long the licensing arrangement lasts, because it does not appear that Kohl's is the destination retailer for Vera Wang customers. However, a May 14, 2009 article in Reuters reported that the exclusive brand strategy that Kohl's continues to pursue is resulting in sales of "better and best price points" according to CEO Kevin Mansell. The importance of exclusive merchandise sales at Kohl's continues to increase, with 44 percent of overall sales going to private brand sales, a significant increase of 200 basis points (Sivaraman, 2009).

Zara on the other hand, has cultivated an air of fashion boutiques without high-end prices and with its own name in place of a designer name. In fact, the average price of an apparel item is under $\$ 30$. Clothes are rarely marked down, improving profit margins. This method appears to be working because of tight vertical integration, a culture of working together, and open sharing of ideas as evidenced by the practice at Zara headquarters where the designers introduce the new outfits for seasons at the office fashion shows (MacMillian, 2006). In March 2009, Zara proved its ability to grow while the competition sinks during the global downturn. Inditex reported a 10 percent gain in sales, increased same store sales, and with a slight increase in gross profit margin (Rohwedder, 2009), a continued reflection of the financial benefits of the lean inventory system managed in-house. Additionally, the recent announcement by Inditex that it would begin to sell Zara merchandise over the Internet in the fall of 2010 can only be viewed as a plus for increasing sales (Bjork, 2009).

\section{LIMITATIONS AND FUTURE RESEARCH}

This research presents a model to better understand the decisions retailers of fast fashion need to make in regard to sourcing choices. It should be useful for those studying retailers to better understand the relationship between sourcing decisions and profitability. Clearly, sourcing decisions have huge implications for merchandising fashion apparel. Some firms might opt for a variation of one of the methods detailed in the model. Future research could explore these variations.

This paper contrasted two firms with very different methods of sourcing. Other investigations could include an array of other fast-fashion firms including $\mathrm{H} \& \mathrm{M}$. This power house retailer, with steady expansion in most regions of the US, would most likely represent the middle part of the model, the house branded approach, contracting with factories of its choice for production of designer labels. Future research could also include expansion of the factors that influence sourcing decisions for fast fashion retailers. Clearly, the fast-fashion concept is important to most retailers and future research could offer insights into customer preferences and retailers profitability.

\section{AUTHOR INFORMATION}

Barbara Mihm is an Associate Professor in Business at the University of Wisconsin Stevens Point. She had 20 years of retail experience prior to her career in education. Her teaching includes both courses in information systems and retail. This research bridges these areas. She has extensive travel experience in Europe and Asia, and is very interested in the dominance of global retailers. She acknowledges the University Professional Development Committee, UW-SP Grant Office, and the UW-System Center for International Business and Economics Research for their support in her on-going research efforts. 


\section{REFERENCES}

1. Agins, T. (2008). The future of luxury; custom fashion, cheap. The Wall Street Journal. 1/4/2007. p.B7.

2. Bitran, B.R., Gurumurthi, S. and Sam ,S.L. (2007). The need for third-party coordination in the supply chain governance. MIT Sloan Management Review. 48(3) Spring 2007.

3. Bjork, C. (2009). Zara is to get big online push. The Wall Street Journal. 9/ 17/ 2009. http://online.wsj.com/article.

4. CNN News. (2009). American Morning. Report on the New York Fashion Industry. 10/19/2009.

5. Capell, K. (2008). Zara thrives by breaking all the rules. Business Week. 10/9/2008.

6. Chang, S. (2007). At Kohl's, Vera Vera should be very wary. Brandweek. 10/16/2006. 47 (37). p.16.

7. Dowsett, S. (2008). Debt-free Zara looks beyond pain in Spain. Times of Malta.com. 10/29/2008. Available online: wwwtimesofmalta.com/articles/view/2008.

8. $\quad$ Friedman, T. (2005). The World is Flat. Farrar, Straus, Giroux. New York, NY.

9. Fry, A., James, A., Briggs, K., Endres, M., Hargrove, A. Marra, K., \& Dion, J. Grear, R. (2007). Company Focus, Zara, in International Retailing, by Sternquist, B. Fairchild. New York, NY.

10. Fung, V.K., Fung W.K. \& Wind, Y.J. (2008). Competing in a Flat World. Wharton. Upper Saddle River, NJ.

11. Helm, B. (2009). 100 Best Global Brands. Business Week. 9/28/2009. p.44

12. Hoovers (2009). Kohl's Corporation. Available online: premium.hoovers.com [5/20/09].

13. Hoovers (2009). Inditex Corporation. Available online: premium.hoovers.com [5/20/09].

14. Industria de Diseno Textil S.A. Inditex Financial Statements. (2008). Available online: http://www.inditex.com/en/shareholders_and_investors/investor_relations/share

15. Keeley, G. \& Clark, A. (2008). Zara overtakes Gap to become the world's largest clothing retailer. Guardian Company. Available online: www.guardian.co.uk/business/2008/aug/11/zara.gap.fashion.

16. Kohl's Company News (2007). Available online: www.kohlscorporatiopn.com/2007PressReleases/News0207Release.htm.

17. Levy, M \& Weitz, B. (2009). Retailing Management. McGraw-Hill Irwin. New York. NY.

18. MacMillan, A ( 2006).. Research collaboration and math model guided intern through 'fast fashion' world. News Office- Massachusetts Institute of Technology. Available online: web.mit.edu.newsoffice/2006/lfmcorrea-1220.html [10/29/08].

19. Moore C.M. \& Fernie J. (2004). Retailing within an international context in International Retail Marketing (eds) Bruce, M., Moore, C. \& Birtwistle, G.Elsevier. Burlingtom, MA.

20. Nolan, K. (2007). Fashion-forward send Kohl's forward-fast. Retailing Today. 9/10/2007. 46(13).p.8

21. O'Connell, V. \& Tan Lu-Lien C. (2008). Exclusive lines may prove risky in cool economy. The Wall Street Journal. 4/11/08. P. B1

22. O'Connell, V. (2007). Boss talk; Is Discount a good fit for Vera Wang? The Wall Street Journal .9/5/2007. P. B1.

23. Rohwedder, C. \& Johnson, K. ( 2008). Pace-setting Zara seeks more speed to fight its rising cheap-chic rivals. The Wall Street Journal. 2/20/2008. P. B1.

24. Sivaraman, A. (2009). Kohl's exclusive brands deft low price theory. Reuters. Available online: wwwreuters.com [5/15/09].

25. The 100 Top Brands (2008). Business Week. 9/29/2008. p. 56.

26. U.S. Department of Commerce, (2006). Office of Textiles and Apparel. 
NOTES 